\title{
Cognitive interviews guide design of a new CAM patient expectations questionnaire
}

\author{
Karen J Sherman ${ }^{1 *}$, Emery R Eaves ${ }^{2}$, Cheryl Ritenbaugh ${ }^{2}$, Clarissa Hsu ${ }^{3}$, Daniel C Cherkin ${ }^{1}$ and Judith A Turner ${ }^{4}$
}

\begin{abstract}
Background: No consistent relationship exists between pre-treatment expectations and therapeutic benefit from various complementary and alternative medicine (CAM) therapies in clinical trials. However, many different expectancy measures have been used in those studies, with no validated questionnaires clearly focused on CAM and pain. We undertook cognitive interviews as part of a process to develop and validate such a questionnaire.

Methods: We reviewed questions about expectations of benefits of acupuncture, chiropractic, massage, or yoga for pain. Components of the questions - verbs, nouns, response options, terms and phrases describing back pain - were identified. Using seven different cognitive interview scripts, we conducted 39 interviews to evaluate how individuals with chronic low back pain understood these individual components in the context of expectancy questions for a therapy they had not yet received. Chosen items were those with the greatest agreement and least confusion among participants, and were closest to the meanings intended by the investigators.
\end{abstract}

Results: The questionnaire drafted for psychometric evaluation had 18 items covering various domains of expectancy. "Back pain" was the most consistently interpreted descriptor for this condition. The most understandable response options were 0-10 scales, a structure used throughout the questionnaire, with 0 always indicating no change, and 10 anchored with an absolute descriptor such as "complete relief". The use of words to describe midpoints was found to be confusing. The word "expect" held different and shifting meanings for participants. Thus paired items comparing "hope" and "realistically expect" were chosen to evaluate 5 different aspects of treatment expectations (back pain; back dysfunction and global effects; impact of back pain on specific areas of life; sleep, mood, and energy; coping). "Impact of back pain" on various areas of life was found to be a consistently meaningful concept, and more global than "interference".

Conclusions: Cognitive interviews identified wordings with considerable agreement among both participants and investigators. Some items widely used in clinical studies had different meanings to participants than investigators, or were confusing to participants. The final 18-item questionnaire is undergoing psychometric evaluation with goals of streamlining as well as identifying best items for use when questionnaire length is constrained.

Keywords: Cognitive interviews, Questionnaires, Expectations, Low back pain, Acupuncture, Chiropractic, Massage therapy, Yoga

\section{Background}

Patient expectations of therapeutic benefit are widely thought to be important determinants of treatment outcomes [1-3]. Some studies have suggested that patient expectations of treatment outcomes are one of the most important prognostic factors for patients with back pain [4-6]. However, results from trials of various complementary and alternative medical (CAM) therapies have

\footnotetext{
* Correspondence: Sherman.k@ghc.org

${ }^{1}$ Group Health Research Institute, 1730 Minor Avenue, Suite 1600, Seattle WA 98101, USA

Full list of author information is available at the end of the article
}

not consistently supported this belief for musculoskeletal pain [7-10]. The lack of a comprehensive theoretical framework for understanding patient expectations [11] and the paucity of measuring instruments that have been evaluated in relation to participant comprehension and interpretation, reproducibility, and construct validity [3] have impeded progress in understanding how expectations may impact treatment outcomes.

There is disagreement in how best to identify, monitor, and classify patients' expectations $[11,12]$. Literature reviews of expectations have reported that when and how 
expectations are elicited matters [12]. Other studies have reported the importance of distinguishing between "probability expectations" (rational projections) and idealized expectations (hopes) [11]. Cognitive interviews have not been used when developing previously validated questionnaires of treatment expectations [13-15], even though cognitive interviews have been used when developing other questionnaires designed to assess patient reported outcomes [16,17]. A recent document from the United States Food and Drug Administration (FDA) recommends cognitive interviews be conducted when developing patient reported outcomes [18].

Here we report our efforts to develop and validate a comprehensive questionnaire for measuring patient expectations of four CAM treatments commonly used for back pain. We chose to focus on back pain because it is the most common musculoskeletal pain condition and the most common pain condition for which people use CAM care [19]. However, we believe that our questionnaire could be modified slightly to capture expectations for other pain conditions.

After reviewing relevant literature and surveying CAM researchers to identify questions that have been used to assess patient expectations of treatments for back pain, we conducted cognitive interviews with low back pain patients to develop and refine questions and identify issues in measurement of patient expectations. Here we describe the content, structure, and meaning of questions and issues identified in cognitive interviews.

\section{Methods}

\section{Selection of categories and domains for testing}

We used two strategies to identify key components of questions for cognitive testing. First, we conducted qualitative interviews with CAM practitioners regarding their experience with and management of patient expectations [20] and with patients seeking CAM about their treatment expectations. Second, KJS and JT collected extant questions related to participant expectations through two mechanisms: literature searches for published questionnaires on patient expectations; and email queries to acupuncture, chiropractic, massage, and yoga researchers in January of 2010 asking for copies of the questions they used to measure expectations in their trials. (See Additional file 1: Appendix A for researchers contacted, and a representative list of their publications).

Our patient interviews included questions about back pain history, changes they hoped to see as a result of treatment, expectations they had for the treatments and whether these differed from their hopes. During data analyses, we extracted themes related to expectations and outcomes from the treatment, including the desire for diminished pain and better ability to engage in meaningful activities. We then compared themes from interviews with those from existing questionnaires and from a literature review and a drafted a conceptual model of patient expectations [20]. We thereby identified areas of importance not addressed by existing questions. Once relevant themes were elucidated, KJS reviewed the original battery of questionnaires from CAM researchers and published questionnaires and created a document with potentially relevant questions. CR and KJS then reviewed these questions and compared them with themes from the interviews. They found all of the extant questions contained potential ambiguities that required evaluation by cognitive interviews to elucidate participant understanding. We therefore deconstructed the questions and responses into components so we could test terms and phrases related to expectations, outcome domains, timeframes for improvement, and response options. Additional file 1: Appendix A contains a list of researchers who provided us with copies of expectancy-related questions they had used in prior studies. Additional file 1: Appendix B contains a list of representative citations for researchers listed in Additional file 1: Appendix A.

\section{Cognitive interview methodology}

Cognitive interviewing, a prominent method in questionnaire development, is used to detect potential problems with survey questions prior to their widespread use [21-24]. Cognitive interview participants are asked to verbally articulate their thought processes related to selection of responses during or immediately after answering specific questionnaire items [17,21,23]. There are two distinct cognitive interviewing paradigms [22,25]. The "Think-aloud" method requires participants to verbalize their thought process in "real time" as they answer a set of sample survey questions. Retrospective probing or "respondent debriefing" [16] requires participants to complete a set of sample survey questions and immediately respond to detailed probes about the questions.

Because researchers disagree about which method is best $[21,23,24]$, we used a combination [25]. For our initial round of interviews, we used retrospective probes to reduce participant burden and to approximate a real experience of responding to actual survey questions. Once we began to finalize terms, response options and question formats, we asked participants to think-aloud as they responded in order to identify additional problems that might not have arisen with our targeted probes. Interviews were conducted via telephone and lasted between 30 and 60 minutes. Each interview contained between 12 and 27 questions, with additional probes depending on the responses.

To refine components of questions into testable questionnaire items, we completed seven rounds of cognitive interviews, each round being concluded when sufficient agreement or disagreement among participants led to 
adjustments of both items and probes. Within each round, we made minor revisions to address emergent problems and gain additional insight into the reason for a particular problem (e.g. adding a probe to learn why participant definitions of a particular term were inconsistent). Each round included 4 to 11 interviews. Interview guides were prepared in advance and interviewers were instructed to follow scripted probes carefully in order to facilitate analysis and comparability [26]. Where unanticipated concerns were elicited, interviewers were instructed to add probes as appropriate [23].

Table 1 lists all specific terms tested in any of the seven rounds of interviews, and their sources. Initially, we asked participants to define terms related to expectations and back pain. Terms included in the first interview guide can be found in Table 1: Terms and phrases describing expectations (with the exception of think is likely to occur which was added later); back pain; and back dysfunction and global effects. We asked participants to define new terms throughout the seven rounds of interviews. Later rounds combined terms, contrasted them with one another, and tested complete questions with response sets in varying combinations and orders. Interview guides typically contained 10-12 sample questions and 4-6 probes for each sample question. To create clear questions for our domains of interest, we tested a variety of combinations of terms and phrases describing expectations, back pain, and our response options.

Table 2 lists terms tested in each round of interviews. Underlined terms were ultimately selected for use in our draft questionnaire. Italicized terms were eliminated in that round of testing. We typically tested each term in multiple rounds of interviews.

Additional tables provide quotations illustrating findings reported in the main text. For most findings, one quotation was selected that best represented overall findings. In situations where we found inconsistent definitions, multiple quotes are often included to illustrate conflicting views.

The following situations raised concerns about specific questionnaire items: (a) inconsistent responses among participants; (b) responses that differed from our a priori expectations; (c) participants reluctant to answer questions or confused about how to do so; or (d) terms or phrases that our participants found to be ambiguous. We continued to test items in cognitive interviews until a satisfactory level of category saturation [27] was reached. Some items were eliminated quickly, but others required multiple adjustments and rounds of questioning before they were either eliminated or included in the final questionnaire. No items were accepted without being tested in at least two rounds of questioning and in varying order within the questionnaire.
Cognitive interviewing is not intended to yield the best possible question, but rather to provide information to facilitate the design of clear and logical questions [21]. After five rounds of interviews, we sought feedback on a draft questionnaire from seven colleagues with expertise in survey design, CAM research, research on chronic pain, and/or patient expectations. After receiving their feedback, we modified the questionnaire and conducted two additional rounds of cognitive interviews (Table 2). We then drafted a cognitively-informed questionnaire that we will test psychometrically.

\section{Interviewers and training}

All four cognitive interviewers had considerable experience in qualitative interviewing and were familiar with the goals of the study. CR had previous experience conducting and analyzing cognitive interviews for questionnaire development [17] and designed and conducted a cognitive interviewer training. Digital recordings were quickly transcribed for immediate review by cognitive interview team members. Rapid turn-around on transcription provided opportunities for assuring comparable interview approach and probing. Weekly teleconference team meetings were the venue for assessing the results of that week's interviews, modifying the interview process as needed in real time, and making prompt decisions for next steps. The high level of interaction among interviewers and investigators assured comparability across interviewers and sites.

\section{Participant recruitment}

We recruited a convenience sample of 39 adults (22 from Arizona, 17 from Washington State) with chronic back pain through recommendations from CAM providers, fliers posted in the community, word of mouth, and internet advertising. Eligibility criteria included: ages 20 to 64; back pain lasting at least 3 months; and no experience with at least one of the four therapies of interest (acupuncture, massage, chiropractic, yoga classes). Participants were not required to be starting a new therapy, but only to express interest in trying one of the four target therapies and to be naïve to that therapy. These inclusion criteria were useful for finding participants who would resemble patients willing to enroll in a clinical trial of CAM. Both the Group Health and University of Arizona Institutional Review Boards determined that these cognitive interviews were "not Human Subjects Research" because the questions were non-sensitive, hypothetical and used for questionnaire development and therefore did not require that we provide formal informed consent. However, prospective participants who responded were provided with a brief description of the study and screened for eligibility. Eligible participants were provided with complete study description, an explanation 
Table 1 Comprehensive list of specific terms tested in cognitive interviews

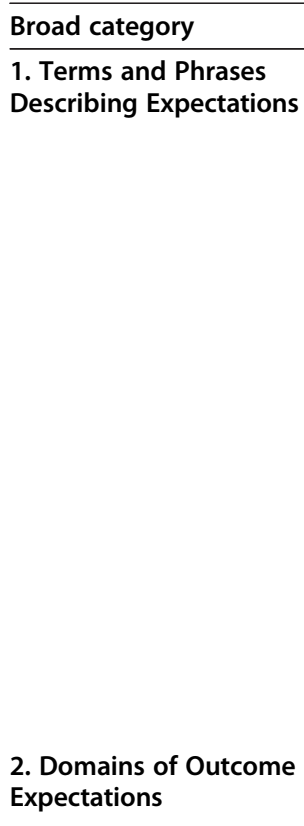

Back Pain

Back Dysfunction and Global Effects

Impact of Back Pain on Specific Areas of Life

Mood, Energy

Coping

3. Timeframe

\section{Specific terms}

Expect

Personally expect

Realistically expect

Hope

hopeful

Think

Feel

Believe

Really think

Successful

Helpful

Think is likely to occur

Confident

Back condition

Back pain

Back pain problems

Limitations due to back pain

Impact of back pain on life

Impact on work

Impact on social and recreational activities

Impact on daily activities

Impact on relationships with family and friends

Mood

Energy

Coping

End of treatment period

Short-term outcome

Long-term outcome

One year from now
1. Response Options

Words

Numbers
Agreement with item

Word descriptors for each gradation

0 to 10

1 to 9

Percentage

-5 to -5

1 to 5
Source for specific terms*

Cambron; Cherkin/Sherman; Coeytaux; Evans; Foster; Haas; Hondras;

Qualitative interviews of patients

Cohen; Linde; Witt

Qualitative interviews of patients

Qualitative interviews of patients

Foster

Cohen; Lao

Borkovec and Nau (Used by Lewith, Wayne and P. White); Cohen

Hondras; Linde; Lao; Vas

Devilly and Borkovec used "really feel"

Borkovec and Nau; Cohen; Devilly and Borkovec; Haas; Kaptchuk; Hurwitz; Lamb

Cherkin/Sherman; Hondras; Ritenbaugh

Devilly and Borkovec; Expert reviewer

Borkovec and Nau (Used by Lewith, Wayne and P. White); Cambron; Cohen; Haas; Hurwitz; Kaptchuk; Lamb

\section{Cherkin/Sherman}

Back pain [Cherkin/Sherman; Foster]

Low back pain [Evans; Hondras; Hurwitz; Williams; Witt]

Low back problems [Hondras]

Devilly and Borkovec

Qualitative interviews of patients

Qualitative interviews of patients

Qualitative interviews of patients

Qualitative interviews of patients

Qualitative interviews of patients

Moyer; Qualitative interviews of patients

Cohen; Mao; Qualitative interviews of patients

Mao

Devilly and Borkovec

Hondras (1 month from now)

Evans (3 months after)

Cherkin/Sherman

Cohen; Mao; Moyer; Vas; White;

Cohen; Cherkin/Sherman; Evans; Foster; Linde ART, Ritenbaugh; Witt; Mao; Lao

Cambron; Coeytaux; Evans; Foster; Hondras

Devilly and Borkovec

Devilly and Borkovec; Evans;

Expert reviewer

Kaptchuk 


\section{Table 1 Comprehensive list of specific terms tested in cognitive interviews (Continued)}

\begin{tabular}{|c|c|c|}
\hline \multicolumn{3}{|l|}{ 2. Anchors } \\
\hline & Relative descriptors & $\begin{array}{l}\text { Lower anchors: A little worse [study team]; Much worse } \\
\text { [Cherkin/Sherman; Hondras]; Very unhelpful [Ritenbaugh]; } \\
\text { Worst pain imaginable [Cambron] }\end{array}$ \\
\hline & & $\begin{array}{l}\text { Upper anchors: Better than it's ever been [study team]; } \\
\text { Extremely helpful [Evans; Ritenbaugh]; Extremely hopeful } \\
\text { [Foster]; Very effective [Coeytaux] }\end{array}$ \\
\hline & Absolute descriptors & $\begin{array}{l}\text { Lower anchors: No pain [Cambron]; Not at all effective } \\
\text { [Coeytaux]; No change/worse [study team]; Not at all helpful } \\
\text { [Williams; Hondras]; Not at all hopeful [Foster]; No Improvement [Witt] }\end{array}$ \\
\hline & & $\begin{array}{l}\text { Upper anchors: Complete Relief [expert reviewers]; } \\
\text { Completely Better [Foster]; Completely Gone [Cherkin/Sherman; Hondras]; } \\
\text { Cure [Linde; Witt]; No pain, pain-free [Cognitive Interviews] }\end{array}$ \\
\hline
\end{tabular}

*For citations and additional information see Additional file 1: Appendix A \& Additional file 1: Appendix B.

of cognitive interviews, and information about privacy and protection of the data collected.

\section{Data analysis}

Cognitive interviews were audio-recorded and transcribed verbatim. Interview transcripts were later coded using qualitative data analysis software (ATLAS.ti, Version 6.0 [28]) by EE, an interviewer experienced in coding and analyzing qualitative data. Coding was helpful for confirming or refuting initial impressions and for organizing the data for presentation to the study team.

Because interviewers had been instructed to use scripted probes and improvised only to elicit additional data, coding was simple and typically aligned with pre-determined domains and areas of interest. 86 codes covered the terms tested (e.g. terms about expectation, response anchors), outcome domains (e.g. back pain, sleep, mood, energy, coping), timeframe and response options (e.g. 0-10 scale, percentage scale, participant defined scale), and comments pertaining to a specific question (e.g. questions originally used by DC and KJS or specific questions created based on participant comments).

\section{Results}

\section{Components of the questions}

\section{Terms and phrases describing expectations}

We tested numerous terms to see how useful they were in eliciting meaningful responses related to expectancy (Table 1). In the first round of interviews, we asked participants to define each term and tell us which they preferred. In later rounds of interviews we continued to clarify which terms were most consistently defined and most meaningful to participants. Table 3 provides relevant quotes for each term.

Originally, we anticipated the term expect, which participants consistently defined as what people think will happen as a result of treatment, would be the best way to ask about this belief. However, after several rounds of cognitive testing, we learned that expect was not actually used consistently when participants responded to sample questions containing the term (Table 3). Some participants answered based on their hopes while others considered both their hopes and expectations. Participants initially defined the terms expect and realistically expect similarly. However when probed, they described realistically expect as more narrowly focused on what one really thinks will happen without consideration of one's hopes (Table 3). Some participants said the word "realistically" made them think about what they really thought would occur.

In cognitive interviews, participants defined hope as what they wished for or wanted to occur at the highest levels of aspiration, unconstrained by reality, prior knowledge or experience (Table 3). Some participants said hope includes emotional aspects of what is expected. By contrast, the term expect is more realistic. Based on these findings, we chose to pair questions about hope with questions about realistically expect in our questionnaire in order to tease apart blind hopes from more realistic beliefs.

One of our expert reviewers recommended we use the phrase think is likely to occur (Table 3) instead of realistically expect. Our participants defined these two phrases similarly. When we compared numerical responses to both survey items, however, we found that participants typically used the same numerical rating for think is likely to occur as they used for the question immediately preceding it (e.g. a high number if it followed a question containing hope; a low number if it followed a question containing realistically expect). In contrast, responses to realistically expect and hope were consistently divided and did not seem to fluctuate with question order. We therefore eliminated think is likely to occur from further consideration. 
Table 2 Decision-making process for eliminating or modifying questions or terms in the rounds of cognitive interviews

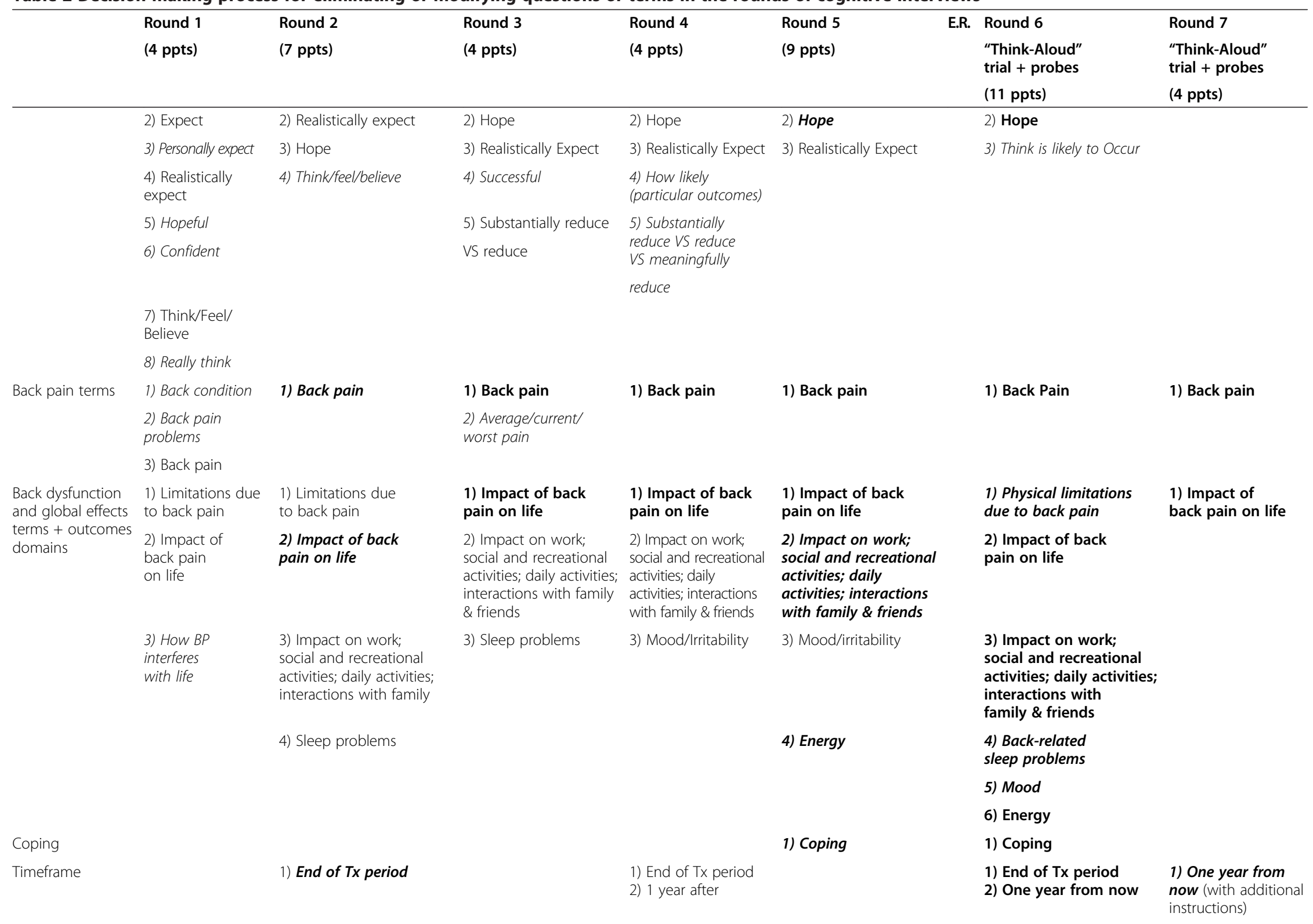


Table 2 Decision-making process for eliminating or modifying questions or terms in the rounds of cognitive interviews (Continued)

\begin{tabular}{|c|c|c|c|c|c|c|c|}
\hline \multirow[t]{6}{*}{ Response options } & $\begin{array}{l}\text { 1) words VS } \\
\text { numbers }\end{array}$ & 1) Ppt defined scales & 1) $0-10$ & 1) $0-10$ & 1) $0-10$ & 1) $0-10$ & 1) $0-10$ \\
\hline & 2) Percent & $\begin{array}{l}\text { 2) Word set } \\
\text { (a little worse- } \\
\text { better than ever) }\end{array}$ & 2) $0-100$ & & & & \\
\hline & \multirow{4}{*}{$\begin{array}{l}\text { 3) Likert scale } \\
\text { (Strongly agree - } \\
\text { strongly disagree) }\end{array}$} & 3) $0-10$ & 3) Percent & & & & \\
\hline & & $\begin{array}{l}\text { 4) Likert scale } \\
\text { (Strongly agree - } \\
\text { strongly disagree) }\end{array}$ & 4) Negative numbers & & & & \\
\hline & & 5) Middle Anchors & & & & & \\
\hline & & 6) $1-9$ & & & & & \\
\hline \multirow[t]{5}{*}{ Word Anchors } & & $\begin{array}{l}\text { 1) } 0=\text { a little worse, } \\
10=\text { better than } \\
\text { it's ever been }\end{array}$ & $\begin{array}{l}\text { 1) } 0=\text { No change, } \\
10=\text { completely } \\
\text { cured/no pain/ } \\
\text { pain-free }\end{array}$ & $\begin{array}{l}\text { 1) } 0=\text { No change, } \\
10=\text { no back pain }\end{array}$ & $\begin{array}{l}\text { 1) } 0=\text { no change, } \\
10=\text { no back pain }\end{array}$ & \multirow[t]{2}{*}{$\begin{array}{l}\text { 1) } 0=\text { no change/worse, } \\
10=\text { complete relief }\end{array}$} & \\
\hline & & & \multirow[t]{4}{*}{$\begin{array}{l}\text { 2) Midpoint Anchor - } \\
\text { somewhat }\end{array}$} & $\begin{array}{l}\text { 2) } 0=\text { No change } \\
10=\text { back pain does } \\
\text { not affect my mood }\end{array}$ & $\begin{array}{l}\text { 2) } 0=\text { no change, } \\
10=\text { back pain no } \\
\text { longer impacts } \text { my life }\end{array}$ & & \\
\hline & & & & $\begin{array}{l}\text { 3) } 0=\text { not at all likely, } \\
10=\text { very likely }\end{array}$ & $\begin{array}{l}\text { 3) Cope VS really cope } \\
\text { VS cope well }\end{array}$ & \multirow{2}{*}{$\begin{array}{l}\text { 2) } 10=\text { back pain no } \\
\text { longer impacts my: (life) } \\
\text { (sleep) (mood/irritability) } \\
\text { (energy) (work) (Social } \\
\text { and recreational activities) } \\
\text { (daily activities) } \\
\text { (relationships) }\end{array}$} & \\
\hline & & & & & 4) $N A$ & & \\
\hline & & & & & & $\begin{array}{l}\text { 3) } 10=\text { Limitations } \\
\text { completely resolved }\end{array}$ & \\
\hline \multirow[t]{2}{*}{ Decisions/Rationale } & & $\begin{array}{l}\text { 1) Acupuncture Expectancy } \\
\text { Scale eliminated - } \\
\text { inconsistent meanings } \\
\text { of questions }\end{array}$ & $\begin{array}{l}\text { 1) Upper anchor } \\
\text { changed to } \\
\text { "no back pain" }\end{array}$ & $\begin{array}{l}\text { 1) "How likely } \\
\text { (specific outcomes)" } \\
\text { was changed to } \\
\text { questions of "how } \\
\text { much change is } \\
\text { expected" }\end{array}$ & $\begin{array}{l}\text { 1) Tested Cherkin/ } \\
\text { Sherman question } \\
\text { "how helpful..." }\end{array}$ & \multirow[t]{2}{*}{$\begin{array}{l}\text { 1) Eliminated: Think is } \\
\text { likely to occur - not as } \\
\text { consistent as realistically } \\
\text { expect }\end{array}$} & \multirow[t]{2}{*}{$\begin{array}{l}\text { 1) Use order suggested } \\
\text { by survey design } \\
\text { expert for self-care } \\
\text { questions }\end{array}$} \\
\hline & & $\begin{array}{l}\text { 2) "Limitations due to } \\
\text { back pain" kept for later, } \\
\text { not tested in all rounds } \\
\text { due to clarity of concept }\end{array}$ & $\begin{array}{l}\text { 2) Ppts prefer same } \\
\text { scale throughout } \\
\text { questionnaire }\end{array}$ & & $\begin{array}{l}\text { 2) Work on Energy } \\
\text { as a domain - test } \\
\text { "energy level" }\end{array}$ & & \\
\hline
\end{tabular}

*Key.

Italicized text = eliminated.

Bold italicized text $=$ selected for use in final questionnaire

E.R. $=$ Expert Review (prior to round 6). 
Table 3 Components of the questions: illustrative quotations for terms and phrases describing expectations

\begin{tabular}{|c|c|c|}
\hline \multicolumn{2}{|c|}{ Term or phrase } & \multirow{2}{*}{$\begin{array}{l}\text { Quote } \\
\text { Expect, is that like another word for hope? Because that's how I'm using it. Do you know what I mean? } \\
\text { Because I'm sort of like, I don't know what to expect, but I sure have a lot of hope. So I think that's, } \\
\text { if this is important for you, I don't know, but that's how I'm using the word expect. AZ-518 }\end{array}$} \\
\hline 3.1 & Expect & \\
\hline 3.2 & Realistically Expect & $\begin{array}{l}\text { If you were to ask me what do I expect, do I talk about what I expect realistically? And then I might } \\
\text { talk about what I hope for. But if you were to ask me, what do I realistically expect, if I just focused } \\
\text { on what is realistic, what is a realistic outcome. SEA-316 }\end{array}$ \\
\hline 3.3 & Hope & $\begin{array}{l}\text { Well so whenever I try a new treatment there's always a hope in the back of my mind that I'm hoping } \\
\text { that I'll be completely free of the back pain and feel completely well. That hasn't been my true experience, } \\
\text { but there's always that hope, you know? AZ- } 427\end{array}$ \\
\hline \multirow[t]{2}{*}{3.4} & Think is likely to occur & $\begin{array}{l}\text { Likely to occur to me, is taking it a little bit more distance and a little bit more objectively. Like, based } \\
\text { on my research, it's likely that I'll have an } 8 \text {, but what do I realistically expect might bring in some more } \\
\text { of my pessimism about what might happen for me." SEA- } 803\end{array}$ \\
\hline & & $\begin{array}{l}\text { "I'd probably say expect [is more meaningful] because likely, I don't know. Likely means, sort of means } \\
\text { to me more like a guess. But expect is more like your opinion." AZ-817 }\end{array}$ \\
\hline 3.5 & Feel & $\begin{array}{l}\text { "Feel" is more vague. Like it's almost more like it's asking you what your intuition is about treatment. } \\
\text { More like a gut reaction as opposed to thinking about it and like, processing all of the information } \\
\text { that you have. SEA-316 }\end{array}$ \\
\hline 3.6 & Think AND Believe & $\begin{array}{l}\text { I don't hear a different in "believe" versus "think". I think you have to be pretty sophisticated to register } \\
\text { a difference on that and so I think in using either verb, it's the same question to me. SEA-531 }\end{array}$ \\
\hline 3.7 & Helpful & Helpful, I guess means steps to recovery, not an instant fix, but something that you work at. AZ-529 \\
\hline 3.8 & Successful & $\begin{array}{l}\text { Either } 95 \text { to } 100 \% \text { pain free. But I would also say it would be successful if it would be a temporary } \\
\text { relief of pain, too. In other words, there'd be a temporary period of relief as opposed to a more } \\
\text { permanent period of relief. SEA-501 }\end{array}$ \\
\hline 3.9 & Confident & I think confident is basically the same thing as hope, but not as positive. AZ-219 \\
\hline
\end{tabular}

Well to me it's contrary to hopeful. I keep going back to that because, to me, wishful is a very soft, gentle word that is not clear. And confident is, I'm confident. Because it's been explained to me. AZ-313

\section{Other terms tested}

Think, feel, and believe (Table 3) were tested as ways to ask participants about their expectations for treatment outcome (e.g. How successful do you feel the treatment will be in relieving your back pain?). We eliminated them because, compared to realistically expect and hope, they did not elicit consistent responses about participant expectations and anticipated outcomes.

Participants found personally expect redundant, since they assumed all questions were about their beliefs. We eliminated really think because participants described feeling as though this questioned their honesty, which this had a negative connotation.

We eliminated helpful, successful, confident, and hopeful because participants defined them inconsistently or we found them less useful in capturing expectations (Table 3). Helpful was defined by some as steps toward relieving pain, and by others as related to consequences of improvement in pain. Successful was defined by some participants as a marked improvement, while others thought this meant that the treatment worked as expected. Success seemed focused on the end of the treatment period and did not imply long-term improvement. Confident was not consistently defined (Table 3). Hopeful was distinct from hope (described above) and was consistently defined as a broadly wishful or optimistic approach. Hopeful is less goal-oriented than hope and we therefore chose to use the term hope in our draft questionnaire due to its association with more specific outcomes.

\section{Domains of outcome expectations Back pain}

In order to assess the usefulness and meaningfulness of different terms used to describe back pain, we cognitively tested several terms or phrases used by past researchers, including: back condition; back pain; and back pain problems (Table 4). In the first round of interviews, participants were asked to describe the meaning of each term or phrase independently, and then to compare them to one another.

Of the three terms describing pain, participants understood back pain most clearly. They consistently defined back pain as the physical experience of pain, while back condition was described as a more anatomical or diagnostic term that some participants did not believe was relevant to their symptom experience. Back pain problems was slightly more ambiguous, referring to the physical problems associated with back pain according to some respondents, and to how back pain interferes with life for others. 
Table 4 Components of the questions: illustrative quotations for domains of outcome expectations

\section{Outcome domain}

4.1 Back Pain

4.1.1 Back Pain

4.1.2 Back Condition

4.1.3 Back Pain Problems

4.1.4 Back pain: average/current/worst

4.2 Back Dysfunction and Global Effects

4.2.1 Limitations due to back pain

4.2.2 How back pain interferes with life

4.2.3 Impact of back pain on life

4.3 Impact of Back Pain on Specific Areas of Life

4.3.1 Comments about how general question about impact of back pain on life was interpreted

4.3.2 Impact on work

4.3.3 Impact on social and recreational activities

4.3.4 Impact on daily activities

4.3.5 Impact on relationships with family and friends

4.4 Sleep, Mood \& Energy

4.4.1 Back-related sleep problems

\section{Quotes}

I would say [back pain]'s more specific to the pain itself, like where it hurts, how it hurts, how often it hurts, the characteristics of the pain. SEA-316

I think back condition could be things that may not be physically felt by the person. Even you know, spinal cord related problems. AZ-219

[Back condition] is pretty broad because it can entail the whole back. From the cervical area all the way down to the sciatic area. AZ-312

Definitely pain, discomfort. Let's see, I know that some sort of alignment of the spine affects it too. Pretty sure that's more medically related. Yeah, I would probably just say pain. AZ-219

Problems, an inability to move, do things, bend over, pick things up, hold grandbabies, pick them up, get up and down off the floor. Things like that. AZ-312

I would say probably more like average pain. But also thinking about those times when I'm particularly uncomfortable...Average was where I went immediately, sort of a global average pain level. AZ-511

Limitations due to back pain makes me think more so of like specific physical activity, general activity limitations, whereas impact is more broad than something like medical, social, physical, like a broader spectrum of effects. SEA-316

What I'm able to do. What limitations do you think of? Not sitting for a long time. In my case, not being able to do certain poses in yoga. And in my case it's mainly sitting. I'm not supposed to sit for a long time. AZ-312

Limitations to me means not being able to do specific tasks, whether it's cleaning the house, bending over, doing yard work, lifting the recyclables. You know, opening a bottle... just being able to do day to day things like you used to do. AZ-313

Kind of like limitations due to back pain. How pain interferes with your life, how the pain affects your life... how back pain interferes is like more active, so it makes me think more of activities. SEA-316

The impact, yeah. I think it's broader, to me, than going right into the specific limitations... More emotional and general life kind of things, than specifically... limitations still to me, deals with something physical. Where impact is I think broader. That opens the door to other things. AZ-313

Activity level, everything, mood, like all levels of my mental state, 'cause when you're in pain, it's like, to be crabby all the time or to be in pain, it's, yeah, and then you can't focus at work, or you know. It affects everything. SEA-515

Well I don't think I was [thinking about emotional impact] until you asked me about it. Until you break it down into all those little pieces. It's important to specify all those questions. Because I think it makes you think about it differently, a little bit. AZ-416

To me, it's a different question because although I may have back pain at work I will exert more through the back pain and work through it, you know what I mean?... If you're having a lot of pain at home, you can opt, "Okay, this day, I won't go gardening out on the rockery" But I might tomorrow, when I feel better. Something like that. But at work, if you have to do the thing today, you're gonna do it. SEA-501

Well, to me [social and recreational activities] sounds like, more about the outside, you know, gardening. Other things that I get enjoyment of out. But when you say life, I think of all aspects of my life. Or in my case, my work. AZ-416

But also the overall quality of life, or however the first one is worded really averages things out, and daily activities I'm thinking about the times that I'm active during the day. Not so much nighttime activities like sleeping. AZ-508

Yeah, because I was thinking impact on my life I was thinking more generally about what I'm able to do. When I started to think about impact on my family I was thinking if I was in less pain, if I had anything better then my family would be much happier. Because I'm also crabbier than I would be if I wasn't in pain. AZ-427

I think I chose slightly higher than what I expected to get from the back. So if my back was a 2 then I chose slightly higher because I feel like any improvement in the pain might make even more improvement in the sleep. AZ-427 


\section{Table 4 Components of the questions: illustrative quotations for domains of outcome expectations (Continued)}

\begin{tabular}{ll}
\hline 4.4 .2 Mood & $\begin{array}{l}\text { Not having back pain would allow me to not be focusing on that pain, and not getting agitated } \\
\text { as easily... I think the treatment itself would also provide a space for me to relax mentally and } \\
\text { physically. Just taking the time to take care of myself, instead of just trudging through the day } \\
\text { with the pain. AZ-508 } \\
\text { Yes, anytime we do anything for my back I want... back pain is an energy suck, and anything } \\
\text { you're doing, I think people are gonna be hopeful that back pain will end up having less energy } \\
\text { drain. SEA-531 }\end{array}$ \\
$\begin{array}{ll}\text { 4.4.3 Energy } \\
\text { 4.5.1 Coping }\end{array}$ & $\begin{array}{l}\text { Coping to me just means how well I'm dealing with the pain. Can I operate even though there } \\
\text { is pain? AZ-530 } \\
\text { When you say "self-care" I think, okay, I need to do things, remembering to stretch and doing } \\
\text { meditation or maybe taking ibuprofen at the end of the day or something, that to me, is self- } \\
\text { care. Coping is just kind of psychologically like, "Can I get through the day? Can I do this activity } \\
\text { that I need to do?" SEA-MP-601 }\end{array}$ \\
\hline
\end{tabular}

\section{Back pain: average/current/worst}

We also tested the value of specifically asking about average pain, worst pain, and current pain (Table 4). When asking participants whether they had described their average pain, current pain or worst pain, most $(6$ of 7) said they had described average pain. While they preferred average pain to the other terms, they preferred to think about areas of highest importance for them, or to answer based on a broader average. Participants had trouble compartmentalizing pain into these categories. They reported it was easier to respond if they could consider both the severity of acute episodes and the constant presence of low or mid-level pain. They did not believe that the term average pain captured these considerations. Based on these findings, we elected to use back pain in our draft questionnaire without additional qualification.

\section{Back dysfunction and global effects}

To evaluate appropriate terms for describing "back dysfunction" [29] and "global improvement" [30] we tested: limitations due to back pain; impact of back pain on your life; and how back pain interferes with your life (Table 4). Participants said both limitations due to back pain and how back pain interferes with your life referred specifically to physical limitations. Limitations and interference were consistently understood to mean physical inability to complete specific tasks. However, the impact of back pain on participants' lives was consistently defined more broadly. It included less tangible aspects of life such as irritability, mood, energy, sleep, and "lightness of being". All of these domains were explicitly not considered to be "interference" and respondents did not include them when answering sample questions about interference. For example, some participants with back pain who continued to do their normal activities reported no interference. However, the same participants reported that the back pain impacted them by increasing irritability, decreasing their enjoyment or "ease and joy" in completing tasks and therefore had a significant impact on their life.

\section{Impacts of back pain on specific areas of life}

We included some questions about expectations related to specific areas of life that back pain could affect but that participants might not have routinely considered as part of general questions about expectations of treatment (Table 4).

Specifically, we tested questions about: (a) impact of back pain on work, including housework; (b) impact of back pain on social and recreational activities; (c) impact of back pain on daily activities; and (e) impact of back pain on relationships with family and friends. Impact of back pain on work was important to include because some participants felt was the most important area of impact while others said they tended to power through pain while at work in ways they could not in other circumstances. Many participants had eliminated sports or other leisure activities from their lives, and did not always consider these activities when responding to general questions about impact of back pain on life. Daily activities were defined by participants as a focus on active times or things that needed attention on a daily basis, rather than on an impact in general. Relationships with family and friends was the domain in which many participants said they were most likely to be impacted by their pain. Families were impacted by negative moods stemming from pain, although this was rarely mentioned in responses to more general questions.

\section{Sleep, mood, and energy}

Poor sleep is a known consequence of back pain for many patients [31]. We used the phrase back-related sleep problems since some participants said they reported sleep problems unrelated to pain (Table 4).

We decided to include questions about mood and energy [30] as some participants reported difficulties in these areas as consequences of back pain (Table 4) [32]. 
Participants' found these terms straightforward. For these two domains, participants reported they might expect treatment to have benefits not directly correlated to reduction in pain.

\section{Coping}

We included coping as a domain of experience because improvement in coping was distinct from improvement in pain (Table 4). Our participants defined coping as the mental ability to carry on in spite of pain. Participants distinguished between coping and self-care very consistently in our interviews. While coping was the ability to handle pain, self-care referred to one's ability to employ various strategies aimed at decreasing or preventing pain.

\section{Timeframe for improvement}

We wanted to assess participants' short-term and longterm expectations. We tried several terms, including end of the treatment period and one year from now. Participants thought the term at the end of the treatment period typically referred to a period between 6 weeks and 6 months, with most (7 of 10) thinking this was 10 weeks to 3 months.

Given the high degree of agreement, we left the end of the treatment period open, though it could be clarified for future studies if needed. To ask about expectations of long-term outcomes, we tested multiple versions of a question about expectations for one year from now. Simply asking what participants expected one year from now was confusing because some participants could not predict long-term outcomes in the absence of knowing the shortterm results. Other participants did not know whether they should include other treatments they might do during the year. We therefore explained that participants should include the current course of treatment they are seeking, plus any self-care or other health care they anticipated completing during that time period. By including this domain in our questionnaire, we can test whether participants expect their treatments would have short term benefits for back pain or would have more lasting benefits.

\section{Components of the responses \\ Response options}

Overall, we found participants preferred response options that were consistent throughout the questionnaire, that numerical options elicited more consistently meaningful responses than word sets, and that numerical rating scales were the most intuitive for participants because they were typically asked about pain on a similar scale in health care settings.

\section{Word sets}

We tested several types of word sets as potential response options (Table 5). Although some participants said they preferred word options, many reported difficulty in remembering the words during their telephone interview. In addition, the meanings of some words differed among participants, and having words define each option made the scales appear non-linear to participants. Finally, participants found it easier to be asked questions using the same scale throughout the interview.

We tested Likert scales reflecting degree of endorsement. Responses included: strongly disagree; moderately disagree; a little disagree; neither agree nor disagree; a little agree; moderately agree; strongly agree (used by $[33,34]$ and more recently by Younger et al. [15]. To test this set of responses, we adapted four items from Mao's validated "Acupuncture Expectancy Scale" expectations of acupuncture [35,36] (Mao) $\left.)^{\mathrm{a}}: 1\right)$ "my pain will improve a lot"; 2) "I will be better able to cope with my pain"; 3) "my pain will go away"; and 4) "my energy level will improve". We discovered that participants were confused about the use of these response options (Table 5 for examples on items 1, 2 and 4). Respondents reported different interpretations of these questions when telling us how they answered these questions. They had trouble reconciling the value judgment in the stem (improve, get better) with a value judgment in the response category (moderately, strongly). Furthermore, when given hypothetical scenarios respondents did not consistently select the same response category.

For example, responses to item 2 (ability to cope) revealed general issues with agree/disagree responses as demonstrated by responses to two scenarios. Scenario (1): Participants were asked, "If you thought your pain would be completely gone, how would you answer this question?" All three participants said they would strongly agree. Scenario (2): participants were asked "If you thought your pain would stay the same but you would have new tools for dealing with it, how would you answer this question?" In response, all three participants also said they would strongly agree. In this example, two different situations elicited the same response. These responses would be hard to interpret if researchers could not distinguish whether a response of "strongly agree" meant a participant expected little relief from pain, but better coping, or significant relief from pain.

\section{Numerical response options}

When asked to define their own scales in response to questions about outcome expectations, all participants selected a numerical scale with the smallest number $(0$ or 1) representing no change and the largest (5 or 10) representing the best possible outcome (Table 5). No participants preferred a 0-100 scale because the large number of choices was too great for general questions about expectations. Some participants conflated percentage with a 100-point scale. Ultimately, we eliminated 
Table 5 Illustrative quotations for response options

\section{Response option \\ Quote}

5.1 Word Sets

5.1.1 Issue: Participant difficulty recalling words

5.1.2 Issues: Meanings of words inconsistent among participants; leads to non-linear scale

Participant attempting to recall response choices: "Disagree strongly, disagree slightly, agree, agree moderately agree slightly, don't have a clue. Don't know what you just said. I would need to have these written down or write them down myself to look at otherwise I can't remember and I spend more time trying to think memorize the answer choices but forget the question." SEA-416

"When you started giving options, I sort of, in my mind, pictured the one going up to ten, so I think your first option was a little worse, if that was the scale, that would be the one. And as it went up, "back feels better than before", from the treatment, I figured that as the ten and you sort of mentioned, the option after that, it sort of felt like it went from one to ten and then sort of went backwards again, it was a natural order in my mind, so, what was the option after "back pain"?" SEA-412

5.2 Agree-Disagree Likert Scale (adapted from Mao [35,36])

5.2.1 Item 1: "My pain will improve a lot"

Respondents confused about how to convey their expectations on this scale; not in agreement about appropriate response

5.2.2 Concerns with interpretation of Item 2: "I will be better able to cope with my pain"

5.2.3 Item 4: "My energy will improve" Responses to scenarios lacked consistency among respondents

5.3 Numerical Response Options

5.3.1 0-10 Scale

\subsubsection{0-100 Scale}

\subsection{Anchors}

5.4.1 Concrete upper anchor, support
"I just felt confused, like do I say I agree with the statement? Do I have to disagree with the statement? I just felt like ugh. I feel like depending on how a question was worded, especially if it was negative I feel like I could easily have said the opposite of what I meant. Just by being confused." AZ-411

Scenario (1): If you only thought your pain would improve a little, what response would you choose?

- I would probably say disagree moderately... I'm disagreeing moderately that my pain will improve a lot, because I'm still trying to keep an open mind but I am sort of feeling like I've tried so many other things that I'm not really sure if it's going to help that much. SEA-410

- Agree slightly. I would endorse it slightly with "A little bit" toward a smaller degree. Then moderate would be sort of, I think the next step up, but not "agree with strongly" which would be a lot of improvement. I think "more slightly" is the lowest degree of positive, if that makes sense. SEA-412

"If I'm not coping anymore do I say strongly disagree or I strongly agree? The question doesn't make sense anymore with an agree, disagree kind of response." AZ-411

Scenario (1): If you thought your energy would increase just a little, what would your response be?

- I slightly agree? When I was trying to say, or moderately agree is what I would respond to try to say it increases a little bit. AZ-411

- I would probably say agree moderately SEA-410

- Neither agree nor disagree SEA-416

- Agree slightly. SEA-412

Scenario (2): If you thought your energy level was fine now, how would you answer that?

- Huh, my energy level is fine, I'd probably say I don't agree to that statement? AZ-411

- I think I'd still slightly agree. SEA-416

- If I felt my energy level was fine, I would say "neither agree nor disagree." SEA-412

"There was a movie out once where they called a girl a "10" because she was very good looking. So zero to ten is kind of, 10 has always been "the best" and zero is "no good". And that's the same scale they use for pain, zero to ten." AZ-813

"I think the one to ten scale is kind of the easiest thing for people to relate to, I don't think people relate very well to using percentages or negative numbers, I think they would just find that confusing. One to 100 seems a little bit arbitrarily more detailed than you need it to be. I mean is somebody gonna choose a 37.4 out of 100 ?" SEA-430

"I like zero to ten better... It was just like, oh, there's so many more numbers to choose from. Like 44 or $88 \ldots$ the question is too general for that sort of precision but there was space for that sort of precision so I was like, oh..." AZ-427

What does "extreme improvement" mean to you? It means total relief. Total relief would be the same thing. Total relief would be better, but extreme improvement is still okay. it still gives me a good idea of what you're asking. AZ-816

I think it was easy, but I'm actually thinking a better word would be total improvement rather than extreme improvement. 'Cause zero's no improvement, so ten would be total improvement. It would be a better choice.' SEA-803 


\section{Table 5 Illustrative quotations for response options (Continued)}

\subsubsection{Lower Anchor: No Change/Worse \\ 5.4.3 Upper Anchor: Complete Relief}

5.4.4 Reliance on midpoint anchor

5.4.5 Discrepancy in midpoint anchor word meaning
If there is no change or getting worse it's going to be zero. If there is like complete relief of pain that's going to be ten. So it makes sense. AZ-529

I think complete relief speaks more clearly. Yeah. Because it's referring to the pain. But then again completely resolved does put it at, it's the main problem in your life too. Which it does create depression and a huge change in everything in your life. So I can also relate to that. AZ-831

I would say completely resolved makes more sense because, well, given my own thoughts about it, because completely resolved to me, means it's not a problem anymore, don't worry about it, complete relief could be, it's good for now, but it might come back later. And I think that resolved is a more solid result. SEA-803

I kind of like relief better, 'cause it really describes more, I think, what people are after with back pain.' SEA-831

I think in some ways when you do that slightly moderately part because the variation is sometimes so little and you have to twist your head around to see how your answer fits with those words-it's hard to pick. I always find myself doing these things to one side of the middle. SEA-416

I thought there was going to- how much improvement- to me the scale, when it was 1 to 10 before I had put two or three as somewhat, but then you changed that to 5 so I chose 5. SO YOU CHOSE 5 BECAUSE I SAID 5 IS SOMEWHAT SUCCESSFUL? Yeah, on a zero to ten I thought of 5 as like $50 \%$ improvement, so to me somewhat successful is a bit less than that. Somewhat successful to me is like 20 to $30 \% .50 \%$ improvement is more noticeable. AZ-427 percentages in order to use a consistent format for all response options. The 0-10 scale was preferred by most participants, being described as more intuitive, more familiar, and allowing them to communicate their anticipated improvement with a reasonable amount of precision.

\section{Anchors}

After determining that participants preferred a 0 to 10 scale, we tested several possible phrases for the upper and lower anchors as well as a possible midpoint (Table 5). Participants preferred word anchors that described absolute amounts of improvement (e.g., "no change" or "complete relief") as opposed to relative improvement (e.g., "worst pain imaginable"). Our anchors were tested and modified over several rounds of interviews to determine the best fit for each question and to elicit the most consistent responses.

We eliminated midpoint anchors because participants often did not agree on the definition of the word and relied too heavily on the midpoint anchor rather than choosing an answer based on their own expectations. One participant changed her answer when a midpoint was used because she perceived that definition was below her idea of the midpoint. For most of our questions, the lower anchor "no change/worse" was clearly understood and elicited the most consistent and meaningful responses. Upper anchors were tailored to specific questions. For back pain related questions, the upper anchor "complete relief" was found to be most clear and consistent. For questions related to limitations due to back pain, we chose "limitations completely resolved" and for questions related to impact of back pain on life we chose "back pain no longer impacts my life". When asking about specific items, we adjusted this anchor to "back pain no longer impacts my: sleep, energy, work, etc". For our coping question (\#8 in draft questionnaire, Additional file 1: Appendix C), "no improvement" to "extreme improvement" was found to be the most meaningful anchor pair after testing several questions and anchor sets. ${ }^{b}$

\section{Overall structure of questions}

In the course of our cognitive interviews, we found that respondents had difficulty specifying the likelihood of a specific outcome (e.g., cure, substantial improvement, better coping). Rather, they wanted to tell us how much improvement they expected. For example, one participant responded to the item, "my pain will improve a lot" by saying that she was "making in [her] mind [her] own rating system which these [response options] represent" (SEA-416) to allow her to communicate how much improvement she expected. Rather than use the response options as intended, she described changing the scale in a way that enabled her to convey the meaning she intended to convey. Another participant, when asked how likely the treatment was to substantially reduce back pain, said "I know that the question was slightly different [from how much improvement do you expect], but ... I think I kind of was answering it the same way. ... In the back of my mind I was thinking about what I expected in terms of relief from pain [rather than speculating on the likelihood of the statement provided]." (AZ-511).

This pattern of participant comments and responses led us to think that the ideal question structure would be: "how much change do you [realistically expect] in your [outcome of interest, e.g. back pain]?" where the bracketed ([ ]) terms could vary. The best response options associated with these questions is a scale of zero to ten where zero is "no change or worse" and ten is "[customized version of relief of the problem, e.g. complete 
relief]". For example: "On a scale of zero to ten, where zero is no change or worse and ten is complete relief, how much change do you realistically expect in your back pain?"

\section{Discussion}

We have presented findings from the cognitive interviewing phase of our study aimed at creating a questionnaire for more accurately measuring patient expectations of CAM therapies. Through these interviews, we gained insight into a number of key problems that might arise with existing questions now used to assess patient expectations in clinical trials. These key difficulties would not have emerged without cognitive interviewing. Key findings from these interviews included: (1) participants used the term expect in an ambiguous way, encompassing both hopes and realistic expectations; (2) participants had difficulty in determining their "average" or "current" pain, in contrast to their lack of difficulty thinking about their back pain in more general terms, i.e. "your back pain"; (3) participants reported a difference between physical limitations and impact of back pain on life and tended not to report important aspects of impact on life when asked only about limitations; (4) participants did not consider some specific areas of impact unless asked directly (e.g. leisure activities); (5) participants identified sleep, mood, and energy as important areas of potential improvement, independent of pain; (6) participants were confused about the meaning of "improvement in coping" (wondering whether "better coping" did or did not imply a decrease in pain); (7) participants had trouble assessing long-term expectations, which were contingent on a number of lifestyle and other factors; (8) participants adapted some categories of response options to convey what they wanted to communicate with researchers rather than providing the information the question was intended to elicit; (9) participants had problems with response options based on word (as opposed to numeric) descriptors both in relation to ability to recall them (in telephone interviews) and to varying interpretations of word meanings; (10) participants preferred anchors that specified absolute amounts of improvement; and (11) participants desired to communicate how much improvement they expected rather than their speculations on the likelihood of specific outcomes. In order to elicit meaningful, consistent responses, questions need to be framed to take these issues into account.

Other researchers have distinguished between "probability expectations" (what participants think is likely to happen) and "value expectations" (what participants want, feel they need, feel they are due, or what they hope for) $[11,12]$. While we did not base our cognitive interview questions on these distinctions, they are useful for explaining the reasoning behind our inclusion of both hope and realistically expect in our questionnaire items.
Since participants seemed compelled to disclose their hopes along with any admission of "realistic" expectations, it was important to ask about both, even if we were primarily interested in the latter. In interviews with individuals beginning a new CAM therapy in an earlier phase of this study, we found that participants often described both their hopes and what they really thought would happen when they were asked what they expected from treatment. Eaves et al. [37] provide a framework for distinguishing between different kinds of hope and show how hope is tightly bound to individuals' assessments of their expectations, experiences, and outcomes of a treatment.

Our findings indicate that cognitive interviews serve an important purpose in survey design. Many questions initially favored by members of the research team and suggested by other experts turned out to present unforeseen interpretation challenges to participants. Our findings are an important reminder to researchers intending to create new questions: researchers' understandings and usages of words and phrases may differ from those of study participants. Cognitive interviews are instrumental for learning how participants will interpret questions and what meanings participants are attempting to convey with their responses. The latter issue is important not only to ensure validity and consistency of responses, but also to ensure that questions capture what is most important to participants.

Our findings have implications for selecting outcome measures for clinical trials evaluating treatments for back pain, especially treatments utilizing novel therapies. They suggest that some standard questions used in back pain research to measure expectations are more challenging for patients to answer and may need to be reconsidered. If corroborated in other patient populations, our findings strongly suggest that some question structures (such as endorsement of the likelihood of particular outcomes) are problematic regardless of whether they have been validated.

Cognitive interviews add unique insights that complement other tools we have for survey development such as open-ended qualitative interviewing and conceptual analysis or quantitative psychometric analysis of survey responses. Cognitive interviews allow for the blending of quantitative and pattern analysis of numerical rating as well as the qualitative aspects of participants' discussions of the meaning of those ratings. For example, we found that asking participants what they thought was "likely to occur" as a result of treatment was problematic. The weakness of this term in eliciting the desired information was revealed only when the numerical responses chosen by participants were compared to their descriptions of their intended response and the changes in descriptions and responses when the order of questions was adjusted. 
Although some researchers may have little experience with this technique and it seems to be infrequently reported, Cognitive Interviewing has been recommended by the Food and Drug Administration (FDA) as part of the development of Patient Reported Outcome (PRO) measures as it is key in ensuring understanding and completeness of conceptual content of questions [18].

In addition to our specific findings, we offer the following insights to researchers planning to conduct cognitive interviews: (1) employing both retrospective probing and "think-aloud" cognitive interviews may elicit a range of issues and help to clarify questions; (2) attention to both participants' descriptions of their response choices and intended meaning as well as to numerical patterns in their responses is key to understanding data after it has been collected; and (3) gaining an understanding of what participants' want researchers to learn, and creating questions that elicit that information, leads to more consistent and meaningful responses.

\section{Limitations}

While we anticipate that our results are broadly applicable among English-speaking North Americans, due to cultural differences in health care and social discourse on pain these results should probably be confirmed in local pilot studies prior to use in other English-speaking countries. Translation into other languages will necessitate additional work using standard protocols for survey translation.

\section{Conclusions}

Our goal of creating a standard questionnaire to measure expectations at the beginning of clinical trials is intended to contribute to understanding the complex relationships of patient expectations and treatment outcomes. The cognitive interview phase of our project has added a level of clarity to our questions that we hope will assist our final questionnaire in eliciting information that is not only meaningful to research participants, but also better suited to provide clear data on the links (if, in fact, there are any) between participant expectations and treatment outcomes.

The final steps in our research include: (1) psychometric evaluation of our draft questionnaire in both clinical and clinical trial populations and (2) analysis of outcomes data collected in clinical trials administering the questionnaire. Once these additional steps have been completed, we will provide the research community with a questionnaire on expectations developed specifically for use in CAM settings that they may choose to use in their own future research.

\section{Endnotes}

aMao's original scale contains the following responses: "not at all agree; a little agree; moderately agree; mostly agree; completely agree", the study team elected to use "strongly disagree; moderately disagree; slightly disagree; neither agree nor disagree; slightly agree; moderately agree; strongly agree".

"We recognize that "extreme improvement" does not fit with our finding that the upper anchor should communicate an absolute amount of improvement. However, as described in relation to Mao's coping question [35] above, improvement in coping is not necessarily correlated to improvements in pain and is therefore problematic. We chose to include this domain, but found that the word anchors that best described this question differed from those in other questions.

\section{Additional file}

Additional file 1: Appendix A. List of researchers responding to requests for contributions of expectancy-related questions used in their clinical trials. Appendix B. Representative citations for authors contributing questionnaire items or with published questionnaires of interest. Appendix C. Draft EXPECT Questionnaire (after Cognitive Testing).

\section{Abbreviations}

CAM: Complementary and alternative medicine; FDA: Food and drug administration; PRO: Patient reported outcome.

\section{Competing interests}

The authors declare they have no competing interests.

\section{Authors' contributions}

KJS is the Principal Investigator; she conceived of and designed the overall study, participated in a review of the literature and contacting CAM researchers for copies of the questions on expectancy they had used in prior studies, participated in creating and revising interview guides, analyzing data, compiling a draft questionnaire, contacting content experts to review the draft questionnaire, and drafting and revising the manuscript. ERE participated in creating and revising the interview guides, interviewing participants, coding and analyzing data, and drafting and revising the manuscript. CR participated in design and conceptualization of the overall study and the cognitive interviewing phase of the study, creating and revising interview guides, training cognitive interviewers, coding and analyzing data, compiling a draft questionnaire, and drafting and revising the manuscript. CH participated in creating and revising interview guides, interviewing participants, compiling a draft questionnaire, and provided important intellectual insight and revision of the manuscript. DC participated in the design of the overall study, contributed important intellectual insight and revisions to the manuscript. JT participated in the design of the overall study, reviewing the literature, contacting content experts to review the draft questionnaire, compiling a draft questionnaire, and contributed important intellectual insight and revisions to the manuscript. All authors read and approved the final manuscript.

\section{Acknowledgements}

The authors would like to thank Rene Hawkes and Melissa Parsons for serving as interviewers and offering their experience in survey creation for this phase of the study. We would also like to thank the participants who completed these very tedious cognitive interviews. We thank the 23 researchers who responded to our request for copies of their questions related to expectations. We thank Carol Greco, Roni Evans, Mark Jensen, Ted Kaptchuk, George Lewith, Charlotte Paterson and Kevin Ulrich for helpful comments on a draft of the survey. This research was funded by the National Center for Complementary and Alternative Medicine (NCCAM) of the National Institutes of Health (R01AT005809). The contents are solely the responsibility of the authors and do not necessarily represent the official views of the $\mathrm{NIH}$. 


\section{Author details}

'Group Health Research Institute, 1730 Minor Avenue, Suite 1600, Seattle WA 98101, USA. ²Department of Family and Community Medicine, University of Arizona, 1450 N Cherry Avenue, Tucson AZ 85719, USA. ${ }^{3}$ Center for Community Health and Evaluation, Group Health Research Institute, 1730 Minor Avenue, Suite 1600, Seattle WA 98101, USA. ${ }^{4}$ Department of Psychiatry and Behavioral Sciences, University of Washington, Box 356560, Seattle WA 98195-6560, USA.

\section{Received: 4 November 2013 Accepted: 17 January 2014}

Published: 25 January 2014

\section{References}

1. Crow R, Gage H, Hampson S, Hart J, Kimber A, Thomas H: The role of expectancies in the placebo effect and their use in the delivery of health care: a systematic review. Health Technol Assess 1999, 3:1-96.

2. Constantino MJ, Arnkoff DB, Glass CR, Ametrano RM, Smith JZ: Expectations. J Clin Psychol 2011, 67:184-192.

3. van Hartingsveld F, Ostelo RWJG, Cuijpers P, de Vos R, Riphagen II, de Vet HCW Treatment-related and patient-related expectations of patients with musculoskeletal disorders: a systematic review of published measurement tools. Clin J Pain 2010, 26:470-488.

4. Bialosky JE, Bishop MD, Cleland JA: Individual expectation: an overlooked, but pertinent, factor in the treatment of individuals experiencing musculoskeletal pain. Phys Ther 2010, 90:1345-1355.

5. Bishop MD, Bialosky JE, Cleland JA: Patient expectations of benefit from common interventions for low back pain and effects on outcome: secondary analysis of a clinical trial of manual therapy interventions. J Man Manip Ther 2011, 19:20-25.

6. Iles R, Davidson M, Taylor N, O'Halloran P: Systematic review of the ability of recovery expectations to predict outcomes in Non-chronic Non-specific Low back pain. J Occup Rehabil 2009, 19:25-40.

7. Kalauokalani D, Cherkin DC, Sherman KJ, Koepsell TD, Deyo RA: Lessons from a trial of acupuncture and massage for Low back pain: patient expectations and treatment effects. Spine 2001, 26:1418-1424.

8. Linde K, Witt CM, Streng A, Weidenhammer W, Wagenpfeil S, Brinkhaus B, Willich SN, Melchart D: The impact of patient expectations on outcomes in four randomized controlled trials of acupuncture in patients with chronic pain. Pain 2007, 128:264-271.

9. Sherman KJ, Cherkin DC, Ichikawa L, Avins AL, Delaney K, Barlow WE, Khalsa PS, Deyo RA: Treatment expectations and preferences as predictors of outcome of acupuncture for chronic back pain. Spine 2010, 35:1471-1477.

10. Thomas KJ, MacPherson H, Thorpe L, Brazier J, Fitter M, Campbell MJ, Roman M, Walters SJ, Nicholl J: Randomised controlled trial of a short course of traditional acupuncture compared with usual care for persistent non-specific low back pain. BMJ 2006, 333:623.

11. Haanstra TM, Hanson L, Evans R, Nes FA, Vet HCW, Cuijpers P, Ostelo RWJG: How do low back pain patients conceptualize their expectations regarding treatment? Content analysis of interviews. Eur Spine J 2013, 22:1986-1995

12. Kravitz RL: Measuring Patients' expectations and requests. Ann Intern Med 2001, 134:881-888.

13. Borkovec TD, Nau SD: Credibility of analogue therapy rationales. J Behav Ther Exp Psychiatry 1972, 3:257-260.

14. Mao J, Armstrong K, Farrar J, Bowman M: Acupuncture expectancy scale: development and preliminary validation in China. EXPLORE 2007, 3:372-377.

15. Younger J, Gandhi V, Hubbard E, Mackey S: Development of the Stanford Expectations of Treatment Scale (SETS): a tool for measuring patient outcome expectancy in clinical trials. Clin Trials 2012, 9:767-776.

16. Irwin DE, Varni JW, Yeatts $K$, DeWalt DA: Cognitive interviewing methodology in the development of a pediatric item bank: a patient reported outcomes measurement information system (PROMIS) study. Health Qual Life Outcomes 2009, 7:1-10.

17. Thompson JJ, Kelly KL, Ritenbaugh C, Hopkins AL, Sims CM, Coons SJ: Developing a patient-centered outcome measure for complementary and alternative medicine therapies II: refining content validity through cognitive interviews. BMC Complement Altern Med 2011, 11:136-153.

18. Guidance for industry: patient-reported outcome measures: use in medical product development to support labeling claims: draft guidance. In Book Guidance for industry: patient-reported outcome measures: use in medical product development to support labeling claims: draft guidance, Volume 4. City: FDA Center for Drug Evaluation and Research; FDA Center for Biologics Evaluation and Research; FDA Center for Devices and Radiological Health; 2006:79.

19. Barnes PM, Bloom B, Nahin RL: Complementary and Alternative Medicine Use Among Adults and Children: United States, 2007. In Book Complementary and Alternative Medicine Use Among Adults and Children: United States, Volume 12. City; 2007:2008.

20. Schafer LM, Hsu C, Eaves ER, Ritenbaugh C, Turner J, Cherkin DC, Sims CM, Sherman $\mathrm{KJ}$ : Complementary and alternative medicine (CAM) providers' views of chronic low back pain patients' expectations of CAM therapies: a qualitative study. BMC Complement Altern Med 2012, 12:234.

21. Beatty PC, Willis GB: Research synthesis: the practice of cognitive interviewing. Pub Opin Q 2007, 71:287-311.

22. Drennan J: Cognitive interviewing: verbal data in the design and pretesting of questionnaires. J Adv Nurs 2003, 42:57-63.

23. Willis GB: Cognitive Interviewing: A Tool for Improving Questionnaire Design Thousands Oaks: Sage Publications; 2005.

24. Conrad F, Blair J, Tracy E: Verbal reports are data! A theoretical approach to cognitive interviews. In Proceedings of the 1999 Federal Committee on Statistical Methodology Research Conference. Washington, DC: Office of Management and Budget; 1999.

25. Renberg T, Kettis Lindblad $\AA$, Tully MP: Testing the validity of a translated pharmaceutical therapy-related quality of life instrument, using qualitative 'think aloud' methodology. J Clin Pharm Ther 2008, 33:279-287.

26. Conrad F, Blair J: Data Quality in Cognitive Interviews: The Case of Verbal Reports. In Methods for Testing and Evaluating Survey Questions. Edited by Presser S, Rothgeb JM, Couper MP, Lessler JT, Martin E, Martin J, Singer E. John Wiley \& Sons, Inc; 2004.

27. Strauss AL, Corbin JM: Basics of Qualitative Research: grounded theory procedures and techniques. Newbury Park, California: Sage Publications; 1990.

28. Muhr T: ATLASti Qualitative Data Analysis Program. In Book ATLASti Qualitative Data Analysis Program. 60th edition. City: ATLAS.ti Scientific Software Development GmbH; 2011.

29. Bombardier C: Outcome assessments in the evaluation of treatment of spinal disorders: summary and general recommendations. Spine 2000, 25:3100-3103.

30. Turk DC, Dworkin RH, Allen RR, Bellamy N, Brandenburg N, Carr DB, Cleeland C, Dionne R, Farrar JT, Galer BS: Core outcome domains for chronic pain clinical trials: IMMPACT recommendations. Pain 2003, 106:337-345.

31. van de Water A, Eadie J, Hurley DA: Investigation of sleep disturbance in chronic low back pain: an age-and gender-matched case-control study over a 7-night period. Man Ther 2011, 16:550-556.

32. White P, Lewith $G$, Hopwood V, Prescott P: The placebo needle, is it a valid and convincing placebo for use in acupuncture trials? A randomised, single-blind, cross-over pilot trial. Pain 2003, 106:401-409

33. Pariente J, White P, Frackowiak RS, Lewith G: Expectancy and belief modulate the neuronal substrates of pain treated by acupuncture. Neuroimage 2005, 25:1161-1167.

34. Moyer CA, Rounds J: The Attitudes toward Massage (ATOM) scale: reliability, validity, and associated findings. J Bodyw Mov Ther 2009 13:22-33.

35. Mao J, Armstrong K, Farrar J, Bowman M: Acupuncture expectancy scale: development and preliminary validation in China. EXPLORE (NY) 2007, 3:372-377.

36. Mao J: Validation of acupuncture expectancy scale in cancer patients. In Book Validation of acupuncture expectancy scale in cancer patients. City; 2009.

37. Eaves ER, Ritenbaugh C, Nichter M, Hopkins AL, Sherman KJ: Modes of hoping: understanding hope and expectation in the context of a clinical trial of complementary and alternative medicine for chronic pain. EXPLORE (NY). In press.

doi:10.1186/1472-6882-14-39

Cite this article as: Sherman et al:: Cognitive interviews guide design of a new CAM patient expectations questionnaire. BMC Complementary and Alternative Medicine 2014 14:39. 